\title{
What do parents of wheezy children understand by "wheeze"?
}

\author{
R S Cane, S C Ranganathan, S A McKenzie
}

\begin{abstract}
Background-Reported wheeze is the cornerstone of asthma diagnosis.

Aims-To determine what parents understand by wheeze.

Methods-Two studies were undertaken: (1) Parents of clinic attendees with reported wheeze $(n=160)$ were asked by questionnaire what they understood by "wheeze" and how they knew their child was wheezy. Responses were compared to definitions of wheeze in 12 epidemiology studies and their response options. (2) The extent of agreement of parents' reports $(n=139)$ of acute wheezing in their children and clinicians" findings of "wheeze" and "asthma" was examined.

Results-(1) "Sound" and "difficulty in breathing" were perceived central to "wheeze". "What you hear" was not selected by $23 \%$ (95\% confidence interval (CI) 16-30\%). "Whistling" was mentioned by $11 \%$ (CI 6-15\%) but featured in 11 of 12 epidemiology questionnaires. (2) There was les than $50 \%$ agreement between parents' and clinicians' reports of wheeze and asthma.

Conclusions-Conceptual understandings of "wheeze" for parents of children with reported wheeze are different from epidemiology definitions. Parents' reports of acute wheeze and clinicians' findings also differ.

(Arch Dis Child 2000;82:327-332)
\end{abstract}

Keywords: wheeze; parents' understanding; proxy reporting; epidemiology

Epidemiology studies conducted in the UK suggest increasing prevalence of childhood wheezing illness ${ }^{1-6}$ and underdiagnosis and undertreatment of asthma. ${ }^{78}$ Reported wheeze is considered central to diagnosing asthma and measuring asthma prevalence. ${ }^{9}$ However, establishing the real prevalence of wheeze is problematic. Estimations could be affected by a number of factors: doctors' and families' perceptions of "wheeze" may change over time"; clinicians more readily diagnosing and prescribing for asthma ${ }^{10}$; the use of "asthma" as a label for wheezy illness ${ }^{11}$; the influence of public health campaigns ${ }^{12}$; and a lower threshold for reporting symptoms ${ }^{6}$ that may also be inaccurate. ${ }^{13}$ Assuming that wheeze could be considered a homogeneous symptom, there are no exact equivalents of wheeze in some languages. ${ }^{1515}$

Several commentaries and reviews have evaluated the effect of these variables on the results of epidemiology studies. They conclude either that they do not completely account for the increase in reported wheeze observed and so the increase must be real, ${ }^{13}$ or that evidence is too weak to support this assertion. ${ }^{9}{ }^{12}$ Some epidemiology studies support parents' reports of wheeze with concordant changes in objective measures such as peak expiratory flow measurements before and after exercise. ${ }^{116}{ }^{17}$ However, the conclusions of many epidemiology studies about wheeze prevalence depend solely on parents' questionnaire responses. ${ }^{3} 5^{18-24}$ Studies examining the reliability of symptom reports vary in their conclusions. Some questionnaires have been shown to be valid. ${ }^{25}$ Other studies suggest caution in their interpretation. ${ }^{26}$ What is unclear is whether parents share epidemiological definitions and clinical labelling of childhood "wheeze".

We hypothesise that parents of wheezy children understand the term "wheeze" differently from epidemiologists and clinicians. The study was divided into two parts: (1) an investigation into what parents of children with reported wheeze understand by wheeze, how each perceives it in their child, and to compare this with epidemiology definitions reviewed; and (2) a comparison of parents' reports of acute wheezing or asthma in children bought to a paediatric Accident and Emergency (A\&E) department with clinicians' findings.

\section{Methods}

STUDY $1 \mathrm{~A}$

A 12 item questionnaire was developed, piloted, and refined, then administered over nine months. The piloting suggested cough was a significant indicator of wheeze and was therefore considered separately from "sounds" in the questionnaire. Unselected parents of children waiting to be seen in a chest clinic were asked to complete a questionnaire. We believed these parents were most likely to know what is meant by wheeze. English is not the first language in about $40 \%$ of attendees' parents. Questionnaire translations supplied by hospital Community Health Advocates, were available in Urdu, Bengali, and Turkish, the main local minority languages. "Squeaking" was used as the nearest equivalent to "wheeze" for the Asian languages. ${ }^{19}$ Patients were referred to the clinic by their family doctor or from $A \& E$. It was unclear whether mention of wheeze in the referral letters meant it had been heard by the clinician or reflected parents' reports, and so letter contents were not analysed. Questionnaires were filled in without prompting. Parents who did not recognise the word wheeze or report wheeze in their child were excluded. 
Table 1 Grouping of responses to open questions

\begin{tabular}{ll}
\hline Grouping & Examples of parents' answers \\
\hline Sound & $\begin{array}{l}\text { Hissing, Squeaking, Whistle, } \\
\text { Rasp, What I hear } \\
\text { Changes in breathing, } \\
\text { Irregular, Different from } \\
\text { usual, Shortness of breath, } \\
\text { Trouble breathing, Heavy } \\
\text { breathing } \\
\text { Coughing } \\
\text { Watery eyes, Cheeks go red, } \\
\text { Upset, Under the weather }\end{array}$ \\
Cough & \\
Unwell &
\end{tabular}

Responses were analysed where a definition of wheeze was given and the majority of the questionnaire had been completed. Questionnaire respondents were anonymous so that parents would not feel "tested" with the potential for fear of differential treatment if they "got it wrong".

\section{STUDY 1B}

Definitions of wheeze and the response options were reviewed in epidemiology studies conducted in the UK and published between 1983 and 1998. Studies were identified using Medline and hand searches. Only studies of childhood respiratory illnesses using parents' proxy reporting by questionnaire were selected. Included is one that was administered by interview. ${ }^{11}$ Studies that referred to other publications for their definitions were included. ${ }^{24} 27$ Studies where definitions were not explicitly reported or referred to were excluded.

STUDY 2

The words most commonly used by parents accompanying children with respiratory problems to A\&E were: cough, difficulty in breathing, noisy breathing, wheeze, chesty, and asthma. A\&E nurses used this list to record parents' presenting complaints on arrival. Clinicians then documented their own findings using the same prompts. Only children reported to or diagnosed with wheeze or asthma have been included.

DATA ANALYSIS

In Study 1A, closed questions had coded response options. Responses to open questions were grouped, classified, and checked for interrater agreement.

In Study 1B, epidemiology questions were examined and classed according to definition type-wheeze defined as "whistling", or

Table 2 Responses to open questions

\begin{tabular}{|c|c|c|c|}
\hline & $\begin{array}{l}\text { What is your idea of } \\
\text { wheeze? } n=160\end{array}$ & $\begin{array}{l}\text { How do you know } \\
\text { your child is } \\
\text { wheezy? } n=160 \\
\text { Response }=159\end{array}$ & $\begin{array}{l}\text { What is the main thing } \\
\text { you notice? } n=160 \\
\text { Response }=148^{\star}\end{array}$ \\
\hline Sound only & $36 \%(28-43)$ & $36 \%(29-44)$ & $18 \%(9-26)$ \\
\hline $\begin{array}{l}\text { Sound with DIB, and/or } \\
\text { unwell/cough }\end{array}$ & $25 \%(18-32)$ & $28 \%(21-35)$ & N/A \\
\hline Cough alone & 0 & 0 & $16 \%(8-25)$ \\
\hline $\begin{array}{l}\text { Cough with } \\
\text { DIB/unwell/sound }\end{array}$ & $4 \%(1-7)$ & $9 \%(5-14)$ & N/A \\
\hline DIB and/or unwell/other & $36 \%(28-43)$ & $26 \%(19-33)$ & $66 \%(55-77)$ \\
\hline $\begin{array}{l}\text { "Whistle" included in } \\
\text { response }\end{array}$ & $11 \%(6-15)$ & $1 \%$ & $1 \%$ \\
\hline $\operatorname{Void}(\mathrm{n})$ & 0 & 1 & 12 \\
\hline
\end{tabular}

N/A, not applicable.

^74 one response; 74 more than one response (N/A). phrased as "wheeze or whistling". Parents' responses were compared with these definitions.

In Study 2, parents' and clinicians' responses were scored as: "exact match" in term(s) used (for example, "asthma"); "reports match findings identified" (for example, "wheeze" and "bronchiolitis"); or "do not correspond". Responses were checked for interrater agreement.

Percentages are reported with $95 \%$ confidence intervals $(\mathrm{CI}) \cdot \chi^{2}$ testing was undertaken where appropriate.

\section{Results}

STUDY $1 \mathrm{~A}$

Parents recorded that their own child was wheezy in 160 of 235 questionnaires administered. Of these 10 were completed in translations. Of the remainder, 41 defined wheeze but recorded their child was not wheezy and 34 were incomplete. Data were not kept on non-respondents.

Most respondents were mothers (76\%; CI $70-83 \%)$, had no other children with wheeze or asthma (79\%; CI 73-86\%), and did not consider themselves wheezy $(68 \%$; CI $60-$ $75 \%)$. Children were aged between 5 months and 16 years (median 4 years 6 months). Responses to questions about age of onset of wheezing were grouped in age bands, as many were imprecise. A total of $88 \%$ (CI 83-93\%) of children had started wheezing before 5 years of age.

Table 1 shows four groupings of responses to open questions: sound, difficulty in breathing (DIB), cough, and unwell. Interrater agreement for grouping was greater than $95 \%$.

Open question groups were then classified as "sound", "sound with other cue(s)", "cough", "cough with other cue(s)", and "DIB and/or unwell" (non-sound) (table 2). This grouping allows for a comparison of parents' responses with definitions in the epidemiology questionnaires which are based on sound (table 4). In response to the open questions, $36 \%$ of parents defined wheeze as a "sound", of which $11 \%$ (CI 6-15\%) mentioned "whistling". A total of $36 \%$ knew their child was wheezy by "sound" alone, $28 \%$ by sound with another cue, $9 \%$ by cough with another cue, and $26 \%$ reported only non-auditory cues (DIB/unwell). There was no relation between the length of time a child had been considered wheezy, and responses to "How do you know your child is wheezy?" grouped as sound, DIB, and sound with DIB $\left(\chi^{2}<2.0 ; p>0.5\right)$. When asked for the main thing they noticed, $66 \%$ of parents used non-auditory cues.

In response to the closed questions (table 3), parents were invited to indicate as many cues as needed to describe how they knew their child was wheezy. A total of $38 \%$ (CI 30-45\%) selected three; $23 \%$ did not select "what you hear". When asked to select one of the cues listed as the main way of knowing their child was wheezing, $40 \%$ (CI 32-48\%) selected "what you hear" and 41\% (CI 33-49\%) chose a non-auditory cue (what they felt and what 
Table 3 Responses to closed questions

\begin{tabular}{|c|c|c|}
\hline & $\begin{array}{l}\text { Do you know your child is wheezy } \\
\text { because ...? (select as many as you } \\
\text { like) } n=160 \text { Response }=159\end{array}$ & $\begin{array}{l}\text { Which is the main way you know } \\
\text { your child is wheezy? (select one) } \\
n=160 \text { Response }=155^{\star}\end{array}$ \\
\hline What you hear & $77 \%(70-83)$ & $40 \%(32-48)$ \\
\hline $\begin{array}{l}\text { What you feel in the } \\
\text { chest }\end{array}$ & $43 \%(35-51)$ & $7 \%(3-11)$ \\
\hline $\begin{array}{l}\text { Because you see difficulty } \\
\text { in breathing }\end{array}$ & $82 \%(76-88)$ & $34 \%(26-42)$ \\
\hline $\begin{array}{l}\text { Because they are } \\
\text { coughing }\end{array}$ & $74 \%(67-81)$ & $19 \%(13-26)$ \\
\hline Void (n) & 1 & 5 \\
\hline $\begin{array}{l}\text { "What you hear" not } \\
\text { indicated }\end{array}$ & $23 \%(16-30)$ & $\mathrm{N} / \mathrm{A}$ \\
\hline Cough not indicated & $25 \%(18-32)$ & $\mathrm{N} / \mathrm{A}$ \\
\hline $\begin{array}{l}\text { Neither "what you hear" } \\
\text { nor "cough" indicated }\end{array}$ & $9 \%(4-13)$ & N/A \\
\hline
\end{tabular}

they saw). Significantly more respondents indicated sound to the closed than to the open "main thing" questions ( $40 \%$ versus $18 \%$; $\mathrm{p}<0.002)$.

Although wheeze translates as "squeaking", results on the 10 translations used suggested that sound was reported less than for the group as a whole, although numbers are too few to say with certainty.

STUDY 1B

Twelve studies reported in the literature were included. Table 4 lists definitions of wheeze and response options. All 12 defined wheeze as an auditory sign, a "sound". Eight studies gave a definition of wheeze of which seven used the word "whistling". These included the following features: audible pitch (noisy breathing, high pitch) with a sound descriptor (whistle, squeak, musical) and location (chest, throat). One study also included "tightness" and "breathlessness". ${ }^{3}$ In the four remaining studies, "whistling" in the chest was given as an alternative to wheeze. A "not sure" response
Table 5 Comparisons of parents' and clinicians' reports of wheeze and asthmo

\begin{tabular}{ll}
\hline & $\%$ \\
\hline Parents and doctor are in agreement & $45(37-53)$ \\
Parents use words other than wheeze/doctor & \\
finds wheeze & $39(31-47)$ \\
- Cough & 19 \\
- Difficulty in breathing & 11 \\
- Chesty & 1 \\
- Coisy breathing & 1 \\
- noisy breathing & 5 \\
- Other & 1 \\
Parents complain of wheeze or asthma/doctor & \\
disagrees & $14(8-20)$ \\
- Clinician finds upper airway noise & 8 \\
- Clinician finds problems not related to & \\
chest & 2 \\
Doctors' response was unclear & 4 \\
\hline
\end{tabular}

option was reported in only one of the 12 studies. $^{28}$

STUDY 2

In 10 months 296 forms were completed at A\&E. Wheeze or asthma was reported in 139 patients by parents and/or clinicians. The remainder had other respiratory symptoms and were excluded from analysis. The children were aged between 4 months and 15 years 9 months (median 2 years 6 months). Interrater agreement for scoring responses was greater than $95 \%$. Parents and clinicians agreed in $45 \%$ of occasions that the patient was wheezy or had asthma. Most disagreement was over reports of cough and upper airway noise (table 5).

\section{Discussion}

From the UK childhood surveys examined here, the prevalence of "current wheeze" (within the last 12 months) ranges from $5.5 \%{ }^{23}$ to $19.6 \%{ }^{19}$ and doctor diagnosed asthma from $1.2 \%{ }^{28}$ to $22.9 \% .^{22}$ However, as we have

Table 4 Definitions and response options for wheeze questions from epidemiology studies of childhood asthma

\begin{tabular}{|c|c|c|c|}
\hline Authors & Reference & Definition of "wheeze" & Response options \\
\hline Venn et al & 3 & $\begin{array}{l}\text { A noisy whistling sound from the chest, not the throat } \\
\text { causing tightness and breathlessness }\end{array}$ & Yes/no \\
\hline Clifford et al & 18 & $\begin{array}{l}\text { Noisy breathing with a whistling sound coming from } \\
\text { the chest, not the throat }\end{array}$ & Not reported \\
\hline Pararajasingam et al & 19 & $\begin{array}{l}\text { Noisy breathing with a whistling or squeaky sound } \\
\text { coming from the chest }\end{array}$ & $0,1-4,5-12,>12$ times \\
\hline Luyt et al & 20 & $\begin{array}{l}\text { Breathing that makes a high pitched musical sound } \\
\text { from the chest, not the throat }\end{array}$ & Not reported \\
\hline Brabin et al & 21 & $\begin{array}{l}\text { Noisy breathing and a whistling sound coming from } \\
\text { the chest, not the throat }\end{array}$ & Not reported \\
\hline Kelly et al & 22 & $\begin{array}{l}\text { Noisy breathing with a whistling sound coming from } \\
\text { the chest or throat }\end{array}$ & Not reported \\
\hline Doull et al & 23 & $\begin{array}{l}\text { Noisy breathing with a whistling sound coming from } \\
\text { the chest and not the throat }\end{array}$ & Quantify frequency \\
\hline Lee et al & 28 & $\begin{array}{l}\text { Noisy breathing with a whistling quality coming from } \\
\text { the chest and not just the throat }\end{array}$ & Yes/no/not sure \\
\hline \multicolumn{4}{|l|}{ "Whistling" alternative } \\
\hline Burney et al & 5 & Does his or her chest ever sound wheezy or whistling? & Not reported \\
\hline Strachan et al & 11 & $\begin{array}{l}\text { Includes ISAAC question "Has this child ever had } \\
\text { wheezing or whistling in the chest at any time in the } \\
\text { past?" }\end{array}$ & Yes/no \\
\hline \multirow[t]{2}{*}{ Powell and Primhak ${ }^{\star}$} & 24 & $\begin{array}{l}\text { (1) Preliminary survey used ISAAC question "Have } \\
\text { you ever had wheezing or whistling in the chest at any } \\
\text { time in the past?" }\end{array}$ & (1) Yes/no \\
\hline & & $\begin{array}{l}\text { (2) Detailed survey uses Usherwood et al-wheeze in } \\
\text { statements not defined }\end{array}$ & $\begin{array}{l}\text { (2) Every/most } / \mathrm{some} / \mathrm{few} \\
\text { days/not at all }\end{array}$ \\
\hline $\begin{array}{l}\text { ISAAC Steering } \\
\text { Committee }{ }^{\star \star}\end{array}$ & 27 & $\begin{array}{l}\text { ISAAC International "Has your child ever had } \\
\text { wheezing or whistling in the chest at any time?" }\end{array}$ & Yes/no \\
\hline
\end{tabular}

Studies UK based or UK as part of international studies.

${ }^{\star}$ Uses the ISAAC key questions and Usherwood et al questionnaire. ${ }^{29}$

${ }^{\star} \star$ Phase 1 for 6-7 year olds. Reported as defined in Asher et al. ${ }^{30}$ 
suggested, reliance on parents' reports in such surveys may be problematic. There may be false negative responses because parents perceive wheeze as something other than the questionnaire definition. There could be false positive responses if parents mislabel noisy breathing owing to stridor, snoring, or other upper airway noise as "wheeze". "Noisy breathing" appeared frequently in the definitions used by the epidemiology questionnaires we reviewed.

To try to clarify what parents understand by wheeze, we chose to ask parents from a large sample of children attending a chest clinic. Within this population are likely to be a large group of children who have wheezed. It is reasonable to assume that parents of these children are more likely to know what wheeze is than a sample of parents from the general population. Although translations were provided, many bilingual parents still preferred to answer in English. Parents who declined to answer a questionnaire included those who spoke languages where translations were unavailable or were illiterate. This is a limitation of this study and of written surveys in general. As "wheeze" does not always directly translate in some languages, it may not make sense to discuss a "non-existent" concept from outside an English framework. However, the problem of defining concepts is not limited to translating between different languages; there are regional differences in the language used to describe symptoms ${ }^{31}$ and differences are likely to exist between different social groupings (age, class, gender) as well as between individuals. ${ }^{15}$ The definitions reviewed in these epidemiology studies show some differences in emphasis although they, and the professional nomenclature of lung sounds, ${ }^{32}$ remain focused on the auditory.

When our respondents were asked to define wheeze, responses of "DIB and/or being unwell" and "sound" scored similarly (36\% each). However, $66 \%$ gave "DIB and/or being unwell" as the main way they knew their child was wheezy. From the equivalent closed question 34\% chose "seeing DIB". Similarly, "what you hear" in the closed question was selected more frequently than the equivalent responses grouped as "sound" to the open question. In other words, responses were more in agreement with the audible clinical concept of wheeze when prompted with a selection. However, in response to the "main thing" questions some respondents to both open and closed questions (86 and 24 of 160 respectively) gave more than one response or left the answer void. Most parents indicated that there were many ways they perceived wheeze in their child (open and closed questions). It is possible that identifying a single cue was for them not appropriate. Perhaps our most important finding was that $23 \%$ of respondents when prompted to select as many cues as needed, did not select "what you hear".

The phrase "wheeze or whistling" in some epidemiology studies implies that wheeze is something other than whistling. ${ }^{33}$ This is different from saying that wheeze is whistling and table 4 reflects this distinction. Our parents rarely mentioned "whistling", even though $45 \%$ of children had wheezed since infancy and presumably had contact with health care workers who might have used the word. Of those who do describe wheeze as "sound", few mention the "whistling" that epidemiology questionnaires usually use to define wheeze. This is not to say that parents would not have answered positively to questions about wheezing in the chest in such surveys. We did not use a prompt of "whistling" in the closed questions but had we done so, we probably would have had positive responses.

Two epidemiology studies said that wheeze came from either the throat or the chest. ${ }^{22} 28$ Stating the chest alone is probably incorrect as "wheeze" may best be heard at the throat. ${ }^{34}$ Only one study provided a "don't know" option to questions about wheeze. ${ }^{28}$ Such an option would allow for the possibility of subjects not understanding or sharing the given definition, nor knowing whether their child has been "wheezy".

Sometimes questionnaires ask questions relating to separate symptoms, for example, cough, wheeze, and breathlessness. ${ }^{22}$ In our study parents seemed to assess wheeze by multiple cues. In questionnaires however, symptoms are listed separately and clinicians also perhaps tend to consider them as discrete. ${ }^{35}$ Although wider definitions can result in misclassifications, ${ }^{36}$ a triad of reported cough, wheeze, and breathlessness ${ }^{22}$ seems to relate best to a diagnosis of asthma when objective measurements have not been made. DIB was offered by respondents more frequently than breathlessness as an answer to our open questions. In a questionnaire, DIB may be a better term than breathlessness as a way of describing altered breathing.

While the first part of the study compared the understandings of parents with definitions given by epidemiologists, the second part compared the labelling of observations of wheeze or asthma by parents and clinicians. Of the $A \& E$ attendees whom clinicians diagnosed as wheezy or having asthma, 39\% of parents described their children's problem with terms other than wheeze or asthma (cough, DIB, chesty or noisy breathing). These descriptors reflect what has been described in the first part of our study and cannot be considered "incorrect". If there is a discrepancy in parents' and doctors' findings when the episode is severe enough for the child to be bought to $\mathrm{A} \& \mathrm{E}$, then it would be reasonable to suggest a similar or greater discrepancy when a child is less unwell and is seen in the community. However, clinicians' findings in A\&E reflect only what is present at the time of examination and not what parents observed before they arrived. Similarly the experience of the clinicians will have varied. It is already known that there is observer variability in clinicians' assessments of clinical features of chest disease. ${ }^{32}{ }^{37} 38$ In our study, $19 \%$ of parents complained of cough where clinicians found "wheeze". Parents are likely to report cough alone when wheeze is heard only on auscultation. Some parents 
reported wheeze or asthma where clinicians found no respiratory abnormalities on examination. This part of our study suggests there are both false positive and false negative reports of wheeze.

Our findings are similar to those of a study in Copenhagen where, using semistructured interviews, the differences in "conceptual vocabulary" between the parents of asthmatic children and clinicians indicated problems in doctor-patient communication. ${ }^{39}$ Asthma vocabulary has also been shown to be different between and within ethnic groups. ${ }^{40}$ Perhaps more widespread use of objective tests for asthma is needed. The reliance of history taking when making a diagnosis of asthma has been questioned..$^{41}{ }^{42}$ A recent review suggested "Let parents use their own words. Do not offer the word 'wheeze' but wait to see if the parents use it. If they do, clarify what it means". ${ }^{43} \mathrm{We}$ suggest that lay understandings of wheeze and the language used to describe it, be considered in both epidemiology and clinical practice.

We thank medical staff for their help, parents for their participation, and Ian Robinson at Brunel University for advice with the questionnaire. Support was received from R\&D NHS North Thames ("Perceived respiratory symptoms in children in east London").

\section{Appendix}

HOW DO YOU KNOW YOUR CHILD IS WHEEZY?

We want to know how parents know their child is wheezy. This is helpful to us in trying to understand asthma and other breathing difficulties.

Please fill in the following information about the child you are here with today. Your answers will be kept strictly confidential.

1. Have you ever heard the word "wheeze"? Yes / No

(If not, do not continue but please hand in this questionnaire)

2. What is your idea of "wheeze"? (Open ended)

3. Has your child ever wheezed? Yes / No

(If not, do not continue with this questionnaire but please hand it in)

4. How do you know your child is wheezy? (Open ended)

5. What is the main thing you notice? (Open ended)

6 . At what age did your child have their first wheezy episode? years month

7. How old is your child now? years ___ months

8. Does this child have any brothers or sisters with chesty problems? If "Yes", please give details. (Open ended)

9. How are you related to the child you are here with?

Please tick one of the following: Mother

Father Relative

Friend Other

10. Do you wheeze? Yes / No

11. To conclude, do you know your child is wheezy because of:

a) what you hear

b) what you feel in the chest

c) because you see difficulty in breathing

d) because they are coughing

Please tick as many as needed.

12. Which one of the above (a, b, c, d) is the main way that you know your child is wheezy?

1 Burr ML, Butland BK, King S, et al. Changes in asthma prevalence: two surveys 15 years apart. Arch Dis Child 1989;64:1452-6.

2 Anderson HR, Butland BK, Strachan DP. Trends in prevalence and severity of childhood asthma. BMF 1994;308: 1600-4.

3 Venn A, Lewis S, Cooper M, et al. Increasing prevalence of wheeze and asthma in Nottingham primary schoolchildren wheeze and asthma in Nottingham primary
4 Ayers JG, Pansari S, Weller PH, et al. A high incidence of asthma and respiratory symptoms in $4-11$ year old asthma and respiratory symptom
children. Respir Med 1992;86:403-7.

5 Burney PGJ, Chinn S, Rona RJ. Has the prevalence of asthma increased in children? Evidence from the national study of health and growth 1973-86. BMF 1990;300:130610 .

6 Whincup PH, Cook DG, Strachan DP, et al. Time trends in respiratory symptoms in childhood over a 24 year period. Arch Dis Child 1993;68:729-34.

7 Speight ANP, Lee DA, Hey EN. Underdiagnosis and undertreatment of asthma in childhood. BMF 1983;286: $1253-5$.

8 Kaur B, Anderson HR, Austin J, et al. Prevalence of asthma symptoms, diagnosis, and treatment in $12-14$ old children across Great Britain (International Study of Asthma and Allergies in Childhood, ISAAC UK). BMF 1998;316:11824.

9 Anderson HR. Is the prevalence of asthma changing? Arch Dis Child 1989;64:172-5.

10 Picciotto A, Hubbard M, Sturdy P, et al. Prescribing for persistent cough in children. Respir Med 1998;92:638-41.

11 Strachan DP, Anderson HR, Limb ES, et al. A national survey of asthma prevalence, severity and treatment in Great Britain. Arch Dis Child 1994;70:174-8.

12 Magnus P, Jaakola JJK. Secular trend in the occurrence of asthma among children and young adults: critical appraisal of repeated cross sectional surveys. BMf 1997;314:1795-9.

13 Britton J. Asthma's changing prevalence. BMF 1992;304: 857-8.

14 Burney P, Chinn S. Developing a new questionnaire for measuring the prevalence and distribution of asthma. Chest 1987;91:79-83S

15 Woolcock A. Epidemiologic methods for measuring prevalence of asthma. Chest 1987;91:89-92S.

16 Austin J, Russell G, Adam MG, et al. Prevalence of asthma and wheeze in the Highlands of Scotland. Arch Dis Child 1994;71:211-16.

17 Jones CO, Qureshi S, Rona RJ, et al. Exercise-induced bronchoconstriction by ethnicity and presence of asthma in British nine year olds. Thorax 1996;51:1134-6.

18 Clifford RD, Radford M, Howqell JB, et al. Prevalence of respiratory symptoms among 7 and 11 year old school children and association with asthma. Arch Dis Child 1989;64: 1118-25.

19 Pararajasingam CD, Sittampalam L, Damani P, et al. Comparison of the prevalence of asthma among Asian and European children in Southampton. Thorax 1992;47:52932.

20 Luyt DK, Burton PR, Simpson H. Epidemiological study of wheeze, doctor diagnosed asthma, and cough in preschool children in Leicestershire. BMF 1993;306:1386-90.

21 Brabin B, Smith M, Milligan P, et al. Respiratory morbidity in Merseyside schoolchildren exposed to coal dust and air in Merseyside schoolchildren exposed to coal

22 Kelly Y, Brabin B, Milligan P, et al. Clinical significance of cough and wheeze in the diagnosis of asthma. Arch Dis Child 1996;75:489-93.

23 Doull IJM, Williams AA, Freezer NJ, et al. Descriptive study of cough, wheeze and school absence in childhood. Thorax 1996;51:630-1.

24 Powell CVE, Primhak RA. Asthma treatment, perceived respiratory disability and morbidity. Arch Dis Child 1995;72:209-13.

25 Jenkins MA, Clarke JR, Carlin JB, et al. Validation of questionnaire and bronchial hyperresponsiveness against respiratory physician assessment in the diagnosis of asthma. Int f Epidemiol 1996;25:609-16.

26 Peat JK, Salome CM, Toelle BG, et al. Reliability of a respiratory history questionnaire and effect of mode of administration on classification of asthma in children. Chest 1992; 102:153-7.

27 The International Study of Asthma and Allergies in Childhood (ISAAC) Steering Committee. Worldwide variations in the prevalence of asthma symptoms: the International Study of Asthma and Allergies in Childhood (ISAAC). Eur Respir F 1998;12:315-35.

28 Lee DA, Winslow NR, Speight ANP, et al. Prevalence and spectrum of asthma in childhood. BMF 1983;286:1256-8.

29 Usherwood TP, Scrimgeour A, Barber JH. Questionnaire to measure perceived symptoms and disability in asthma. Arch Dis Child 1990;65:779-81.

30 Asher MI, Keil U, Anderson HR, et al. International study of asthma and allergies in childhood (ISAAC); rationale and methods. Eur Respir 7 1995;8:483-91.

31 Weiland SK, Kugler J, von Mutius E, et al. The language of pediatric asthma patients. A study of symptom description. [In German]. Monatsschr Kinderheilkd 1993;141:878-82.

32 Pasterkamp H, Montgomery M, Wiebicke W. Nomenclature used by health care professionals to describe breath sounds in asthma. Chest 987;92:346-52.

33 Clifford R. Respiratory sections of questionnaires are imprecise. BMF 1996;313:814

34 Meslier N, Charbonneau G, Racineux J-L. Wheezes. Eur Respir f 1984;8:1942-8.

35 Green J. Commentary: Generalisability and validity in qualitative research. BMF 1999;319:421.

36 Lupton D. Medicine as culture: illness, disease and the body in Western societies. London: Sage Publications, 1994:101.

37 Wang EEL, Milner RA, Navas L, et al. Observer agreement for respiratory signs and oximetry in infants hospitalized with lower respiratory infections. Am Rev Respir Dis 1992; 145:106-9. 
38 Spiteri MA, Cook DG, Clarke SW. Reliability of eliciting physical signs in examination of the chest. Lancet

39 Ostergaard MS. Childhood asthma: parents' perspective-a qualitative interview study. Fam Pract 1998;15:153-7.

40 Hardie GE. The future of asthma [editorial]. Lancet 1997;350:1113
41 Dales RE, Nunes F, Partyka D, et al. Clinical prediction of airways hyperresponsiveness. Chest 1988;93:984-6.

2 Pratter MR, Hingston DM, Irwin RS. Dingosis of bronchial asthma by clinical evaluation: an unreliable method. Chest 1983;84:42-7.

43 Keeley DJ, Silverman M. Are we too ready to diagnose asthma in children? Thorax 1999;54:625-8. 